\title{
KRAEMER Gilles. 2000. La presse francophone en Méditerranée (avec une préface de Paul Balta). Paris : Maisonneuve et Larose.
}

André Reboullet

\section{(2) OpenEdition}

Journals

Édition électronique

URL : https://journals.openedition.org/dhfles/2332

DOI : $10.4000 /$ dhfles.2332

ISSN : 2221-4038

Éditeur

Société Internationale pour l'Histoire du Français Langue Étrangère ou Seconde

Édition imprimée

Date de publication : 1 décembre 2002

Pagination : 180-181

ISSN : 0992-7654

\section{Référence électronique}

André Reboullet, « KRAEMER Gilles. 2000. La presse francophone en Méditerranée (avec une préface de Paul Balta). Paris : Maisonneuve et Larose. », Documents pour l'histoire du français langue étrangère ou seconde [En ligne], 29 | 2002, mis en ligne le 15 mai 2014, consulté le 27 mai 2021. URL : http:// journals.openedition.org/dhfles/2332 ; DOI : https://doi.org/10.4000/dhfles.2332

Ce document a été généré automatiquement le 27 mai 2021.

(c) SIHFLES 


\title{
KRAEMER Gilles. 2000. La presse francophone en Méditerranée (avec une préface de Paul Balta). Paris : Maisonneuve et Larose.
}

\author{
André Reboullet
}

1 Gilles Kraemer est journaliste, docteur en sciences de l'information et chargé de la coopération internationale au centre de formation et de perfectionnement des journalistes (Paris). Il a enseigné à l'Université libanaise, à l'Université du Caire et a travaillé dans la presse égyptienne francophone. L'ouvrage ici proposé est une réduction de la thèse de doctorat que l'auteur a soutenue à l'Université de Paris II (avril 2001).

2 Paul Balta dans la préface se trouve confronté à une étrangeté, un paradoxe, d'aucuns diront « un miracle » : la presse francophone en Méditerranée (P.F.M.) répartie sur six pays (le Maroc, l'Algérie, la Tunisie, l'Egypte, le Liban et la région autonome du Val d'Aoste) remonte, pour les titres les plus anciens, à la fin du XVIII siècle; mais «le miracle» est que dans les années $90 \mathrm{du} \mathrm{xx}^{\mathrm{e}}$ siècle, $50 \%$ au moins des titres actuels de cette presse ont été créés. Paradoxe, parce que tout dans ce contexte récent était défavorable à l'éclosion d'une presse nouvelle :

- les indépendances de nations nouvelles qui ont choisi la voie de l'arabisation

- la mondialisation et la prégnance de l'anglais.

« Paradoxe » interrogé par Gille Kraemer, qui, dès l'introduction, énumère les questions qu'il suggère : d'où vient cette presse francophone dans les pays de la Méditerranée ? Ses conditions d'apparition d'hier sont-elles les mêmes aujourd'hui? Y a-t-il des différences autres que simplement linguistiques entre la presse d'expression française et celle en langue nationale? Comment ces journaux francophones justifient-ils leur authenticité et leur identité nationales? Jouent-ils un rôle social que n'assurent pas les journaux en langue nationale? Et si c'est le cas, pour quelles raisons et dans quels contextes? 
$4 \quad$ L'ouvrage apporte des réponses à ces questions et les répartit en cinq chapitres.

- Le poids de l'histoire et la rupture de la Modernité.

- Une presse francophone au milieu des conflits linguistiques.

- Les liaisons dangereuses de la presse et de l'Etat.

- Presse communautaire et presse nationale.

- Une presse plus locale que globale.

5 On relèvera dans le dernier chapitre les appréciations plus que réservées de cette presse sur la notion et les institutions de la francophonie.

6 La presse francophone en Méditerranée est un ouvrage rigoureux, minutieux, ouvrant de nombreuses perspectives de recherche. Très complet et fiable, il a toutes les chances de rester pour longtemps l'« ouvrage de référence » sur la question. 